\title{
Risk factors for fatal and nonfatal repetition of suicide attempts: a literature review
}

\author{
This article was published in the following Dove Press journal: \\ Neuropsychiatric Disease and Treatment \\ 7 November 2013 \\ Number of times this article has been viewed
}

\section{Massimiliano Beghi ${ }^{1,2}$ \\ Jerrold F Rosenbaum ${ }^{3}$ \\ Cesare Cerri ${ }^{1,4}$ \\ Cesare M Cornaggia ${ }^{1,5}$}

'Psychiatry Clinic, University of Milano Bicocca, Milan, Italy;

${ }^{2}$ Department of Psychiatry, Salvini Hospital, Rho, Italy; ${ }^{3}$ Massachusetts

General Hospital, Harvard

Medical School, Boston, MA, USA;

${ }^{4}$ Department of Rehabilitation

Medicine, Zucchi Clinical Institute,

Carate Brianza, Italy; ${ }^{5}$ Forensic

Psychiatric Hospital, Castiglione delle

Stiviere, Mantua, Italy
Correspondence: Massimiliano Beghi Psychosocial Center,

28 Via Beatrice d'Este, Rho, Milan, Italy

Tel +3902994303919

Fax +390293182492

Email mbeghi@aogarbagnate.lombardia.it
Objectives: This review aimed to identify the evidence for predictors of repetition of suicide attempts, and more specifically for subsequent completed suicide.

Methods: We conducted a literature search of PubMed and Embase between January 1, 1991 and December 31, 2009, and we excluded studies investigating only special populations (eg, male and female only, children and adolescents, elderly, a specific psychiatric disorder) and studies with sample size fewer than 50 patients.

Results: The strongest predictor of a repeated attempt is a previous attempt, followed by being a victim of sexual abuse, poor global functioning, having a psychiatric disorder, being on psychiatric treatment, depression, anxiety, and alcohol abuse or dependence. For other variables examined (Caucasian ethnicity, having a criminal record, having any mood disorders, bad family environment, and impulsivity) there are indications for a putative correlation as well. For completed suicide, the strongest predictors are older age, suicide ideation, and history of suicide attempt. Living alone, male sex, and alcohol abuse are weakly predictive with a positive correlation (but sustained by very scarce data) for poor impulsivity and a somatic diagnosis.

Conclusion: It is difficult to find predictors for repetition of nonfatal suicide attempts, and even more difficult to identify predictors of completed suicide. Suicide ideation and alcohol or substance abuse/dependence, which are, along with depression, the most consistent predictors for initial nonfatal attempt and suicide, are not consistently reported to be very strong predictors for nonfatal repetition.

Keywords: suicide, deliberate self-harm, suicide attempt, repetition, predictors

\section{Introduction}

In recent years, suicide-attempt (SA) rates have been widely studied. A World Health Organization community survey reported the lifetime prevalence of SAs at $0.4 \%-4.2 \%$. ${ }^{1}$ Female sex, young age, marital status (divorced or widowed), and having a personality disorder have been associated with an increased risk of attempting suicide.

The incidence rate for completed suicide (S) is $11.2 / 100,000,{ }^{2}$ increases with age, and is three times higher in males than in females. ${ }^{3}$ Suicide accounts for about $1 \%$ of all deaths and is the ninth-leading cause of death in the US and the third in ages 15-24 years. ${ }^{3,4}$ Rates in Caucasians are twice those of non-Caucasian populations, and married people are less likely than single, divorced, or widowed to commit suicide. ${ }^{2}$ For those in bereavement, the risk is higher in the first year after loss. Rates are higher in Protestants $(31.4 / 100,000)$ than in Catholics $(10.9 / 100,000)$ or Jews $(15.5 / 100,000)$. Unemployment increases the rate of suicide by $50 \%{ }^{3}$ 
The suicide risk is higher in psychiatric patients compared to nonpsychiatric populations. More specifically, lifetime risk of suicide has been reported as high as $15 \%$ for affective disorders, $10 \%$ for schizophrenia, and $2 \%-3 \%$ for alcohol abuse. ${ }^{4}$ With respect to affective disorders, the risk is higher with increasing severity of depression. Suicides occur more often in patients with a family history of suicide, mood disorders, and alcohol abuse. ${ }^{4}$ Suicidality tends to emerge early in the course of a mood disorder, and increases in association with melancholia and agitation. ${ }^{4}$

Despite these many variables having been associated with suicidal behavior, their usefulness in predicting future suicidal behavior remains undemonstrated. The prospective prediction of later suicide remains difficult. ${ }^{5,6} \mathrm{~A}$ need exists, as underlined by Hughes and Owens, ${ }^{6}$ for more effective monitoring of people who contact hospitals because of SAs, and for more information on patients who carry out SAs but do not attend hospital. The likelihood of a repeated attempt after a first SA has been investigated less extensively. An episode of self-harm is a strong predictor of later suicide, with the risk peaking in the first 6 months after a self-harming episode, but risk persists for many decades.

A recent review estimated the 1 -year incidence of repetition at $16 \%$ and fatal repetition at $2 \%$ of attempters. ${ }^{7}$ After 9 years, the suicide-fatality rate increased to more than $5 \%$. Both fatal and nonfatal repetition rates were reported to be lower in Mediterranean than in Northern European countries. ${ }^{8}$

However, despite the potential importance of studies investigating the risk factors involved in repetition of SA, no systematic reviews of the issue have been reported. Accordingly, the aim of this review was to identify the evidence for predictors of repetition of SA, and more specifically for subsequent $\mathrm{S}$.

\section{Methods}

One of the authors (MB) searched both PubMed and Embase systematically for studies carried out between January 1, 1991 and 31 December, 2009 in English, using the keywords repetition/repeated suicide attempt, repetition/repeated selfharm, recurrence/recurrent self-harm, recurrence/recurrent suicide attempt, repetition/repeated self-poisoning, and recurrence/recurrent self-poisoning. Suicides in most primary studies included those that were definite (by verdict of a coroner or equivalent authority) or probable (open verdict or equivalent judgment); definitions were too variable for us to discriminate further, and we have included them all and used this broad definition of suicide. With the terms "suicide attempt" or "SA," any nonfatal act in which the patient causes self-harm (self-mutilation, poisoning, jumping from high places, firearm shots, hanging, asphyxiation) was considered. The nomenclature has been taken from Silverman et al; we considered all suicidal acts, despite the degree of suicidal intent. With the term "SA" we mean a not-completed suicide (with or without injuries), while with the term "S" we mean a completed suicide. ${ }^{9,10}$

For the aim of this study, we included cohort studies, case-control studies, and cross-sectional studies. Since our review focused on environmental risk factors and not on management, we excluded studies investigating self-harm management and/or care. Moreover, some of these studies investigated selected populations at risk, and others had very small samples. Thus, we decided to exclude studies investigating selected populations (childhood/adolescence, elderly, males/females only, minorities only, patients with a specific personality disorder), studies with small samples (fewer than 50), or prospective studies with a follow-up shorter than 6 months. We decided to exclude special populations because the aim of the review was the prospective prediction of later suicide in the whole population referring to the emergency room.

Studies on self-poisoning only were included because the self-poisoning method encompasses $80 \%$ of females' and $64 \%$ of males' SAs. ${ }^{8}$ For the same reason, we decided to include studies on adults only.

\section{Data extraction}

After a first screening, 211 papers satisfied our inclusion criteria. Six were useful for the introduction and for the discussion. The majority of them were carried out in Europe. Since designs, the variables studied, and the length of follow-up were different among these studies, a formal meta-analysis or direct comparison was not possible. After excluding 53 studies for not fulfilling the scope of the review, five studies for small sample size, 72 studies for a selected sample ( 37 childhood/ adolescence, ten elderly, three females only, one males only, 19 patients with a psychiatric diagnosis, two minorities), we were left with 76 studies: 13 (17\%) with a cohort analysis, 45 (59\%) with a case-control analysis, and 18 (24\%) with a cross-sectional analysis (Figure 1).

Sixty of them (79\%) were carried out in Europe, more specifically, 24 in the UK, 20 in Scandinavian countries, five in Ireland, two in France, one in Spain, one in the Netherlands, one in Belgium, and six in three or more countries. The other studies were done in the US (five), Australia (four), Canada (two), the People's Republic of China (two), Iran (one), 
Brazil (one), and Uganda (one). SA was investigated in 64, while $\mathrm{S}$ was investigated in 18 studies.

All the risk factors investigated in the studies were inserted and then selected by a consensus-based process (by all the authors).

\section{Results \\ Nonfatal repetition}

The strongest predictor for nonfatal repetition was a history of SA, a finding reported as significant in 13 of 16 multivariate analyses and 13 of 14 univariate analyses (Table 1). Also significant were being a victim of a sexual abuse (multivariate $5 / 9$, univariate $4 / 5$ ), poor global functioning (multivariate $3 / 4$, univariate $4 / 4$ ), having a psychiatric disorder (multivariate 5/11, univariate 6/11), undergoing psychiatric treatment (multivariate $2 / 7$, univariate $7 / 8$ ), depression (multivariate $3 / 10$, univariate $8 / 12$ ), anxiety (multivariate $2 / 6$, univariate $4 / 5$ ), or alcohol abuse or dependence (multivariate $4 / 10$, univariate $4 / 8$ ). There were weaker associations for having a personality disorder, repetition for young adult age, unmarried status, alcohol abuse or dependence, psychiatric morbidity or treatment, and unemployment status. For many variables (Caucasian ethnicity, having a criminal record, having any mood disorders, bad family environment, and impulsivity) there are indications for a correlation, but data are very scarce. The results of analyses are in Table 1.

\section{Completed suicide}

The strongest predictors of $\mathrm{S}$ are older age (multivariate $9 / 16$, univariate $2 / 5$ ), a high suicide ideation (multivariate 5/9, univariate $1 / 2$ ), a history of SA (multivariate $7 / 11$, univariate 1/5). Living alone, male sex, and alcohol abuse are weaker predictors. There is a correlation (but supported by very scarce data) for poor impulsivity and having a somatic diagnosis. There are no data available for sexual and physical abuse during childhood or for the family environment. The syntheses of the available results are in Table 2.

\section{Discussion}

At present, there is no psychological test, clinical technique, or biological marker sensitive and specific enough to predict either short-term suicide or repetition. In line with Appleby et $\mathrm{al}^{3}{ }^{3}$ there is a north-south gradient in the repetition rate of suicide. A study by Pokorny ${ }^{5}$ illustrates how a method to predict suicide based on recognized risk factors will not only lead to a better identification of individuals at risk but also to a higher number of lost-to-follow-up or undetected cases. In this study, the authors attempted to identify which of 4,800 consecutive patients would commit suicide. On the basis of 21 risk factors, they identified 803 patients having increased risk of suicide. Thirty of 803 (3.7\%) committed suicide in a 5-year follow-up. None of these risk factors was detected in $37 / 67$ suicides. These results are confirmed by a review of twelve studies conducted by Diekstra in $1985 .{ }^{85}$ About $50 \%$ of suicidal people had committed at least one previous attempt. Also in this review, it is shown that it is easier to detect a nonfatal SA than a fatal one. This means that $\mathrm{S}$ is multifactorial, and involves not only medical but also philosophical aspects, eg, life is or is not worth living, and it is often a difficult but aware choice. The goal of a suicide assessment is not to predict suicide, but to place a person along a putative risk continuum to evaluate suicidality, especially in the period immediately following the attempt, and allow for a more informed intervention. In fact, according to Reulbach and Bleich, ${ }^{86}$ up to $45 \%$ of people who deliberately harm themselves leave accident and emergency departments without receiving an adequate psychiatric assessment; after the discharge, the patients should not be lost in aftercare, especially if they suffer from depression, bipolar disorder, or schizophrenia. ${ }^{86}$

In fact, after adjustment for baseline demographic and clinical characteristics and hospital differences, being referred for specialist follow-up was associated with reduction in repetition rate. ${ }^{87}$

\section{Synthesis of the available results}

It is difficult to identify risk factors for repetition of nonfatal $\mathrm{SA}$, and even more for repetition ending in $\mathrm{S}$. The studies evaluated in this review had different designs and followup, so they are not comparable for a systematic review with meta-analysis of the available data. However, some intriguing results are available. Alcohol/substance abuse or dependence and suicide ideation, which are, along with depressed mood, the most consistent predictors for self-harm and suicide, ${ }^{4}$ do not seem as strong for nonfatal repetition. The presence of a previous SA is a more consistent finding for nonfatal repetition than for $\mathrm{S}$, but it is the best risk factor for both and persists for many decades. The presence of a personality disorder, depression, sexual abuse in childhood, alcohol dependence, or unemployed or unmarried status are more consistently significant in nonfatal than in fatal SAs, while in nonrepeated SA, having a personality disorder increased rates among both fatal and nonfatal attempts. ${ }^{4}$ Impulsivity seems to be correlated with SA and inversely correlated with suicide completion. On the other hand, having a suicide ideation, (older) age, and (male) sex are thought to be 
more consistently found in fatal repetition, although the role of sex is not very clear. Female sex and younger age, in contrast with data on nonfatal SA, are not likely to predict repetition. This means that once a first SA has been made (an event more frequent in females and younger people), the risk for a second attempt does not appear increased in these two categories.

Other variables, such as family environment, problemsolving, and global functioning, have a positive correlation with fatal and/or nonfatal SA repetition, but data available are not sufficient to identify them as "predictors" of repetition. Further studies are needed to confirm this correlation.

\section{Methodological pitfalls}

Many other variables have been studied, eg, Caucasians commit suicide twice as frequently as other races, and Protestants are more likely to commit suicide than Catholics or Jews. ${ }^{4}$ A nonheterosexual orientation carries an increased risk for attempted but not for completed SAs. ${ }^{4}$ In all these cases, data on SA repetition are inconsistently reported.

Moreover, since a previous SA is the best risk factor for both fatal and nonfatal repetition, most findings presented here might not be specific to repetition. Only three studies in our group investigated the risk factors in first attempters for future attempts, ${ }^{38,45,78}$ and only one ${ }^{45}$ studied it prospectively.

According to Owens et $\mathrm{al}^{7}{ }^{7}$ the median proportion of patients repeating nonfatal SA is $16 \%$ at 1 year and $23 \%$ in studies lasting longer than 4 years. For a subsequent suicide, after a longer follow-up, the suicide rate increases from less than $2 \%$ at 1 year to more than $5 \%$ in studies lasting over
9 years. However, as most prospective studies lasted 1 year, the risk factors for $\mathrm{S}$ in subsequent years may differ from those detected at early follow-up.

\section{Future perspectives}

Further studies would ideally examine a well-defined inception cohort (ie, patients at time of first SA) identified and followed prospectively. A long-term follow-up (at least 4 years) is recommended. Standard definitions of risk and prognostic factors should be determined when planning the study. Interacting factors such as previous attempts or selected samples should be controlled for at the planning or the analysis stage. Some variables, like sexual child abuse, family environment, problem-solving, and global functioning, should be included, to evaluate their role for a repeated episode. Ideally, a study would compare different ethnicities and religions and investigate the differences in suicide repetition between immigrants and nonimmigrants. Sexual orientation should be investigated as well.

\section{Conclusion}

SA repetition (whether fatal or nonfatal) is a common event in developed countries. Prediction of recurrent SA in a patient who committed a first SA is an important task for the psychiatrist. However, it is hard to find independent predictors out of all the many variables associated with repeated and especially with $\mathrm{S}$. Based on the available evidence, only a previous SA, depression, sexual abuse in childhood, and personality disorders have been found to predict nonfatal SA, while previous SA and older age were found to predict fatal SA. Suicidal ideation, which is one of the most consistent

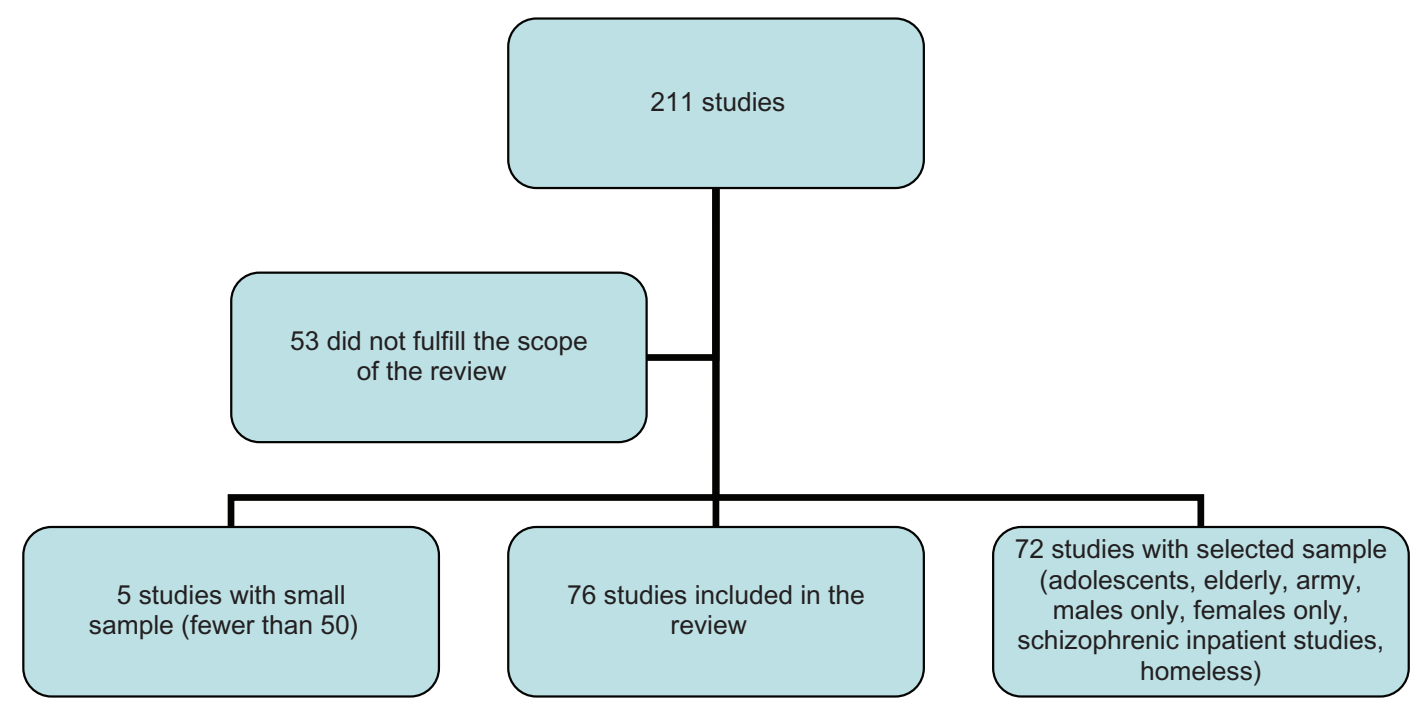

Figure I Literature review. 


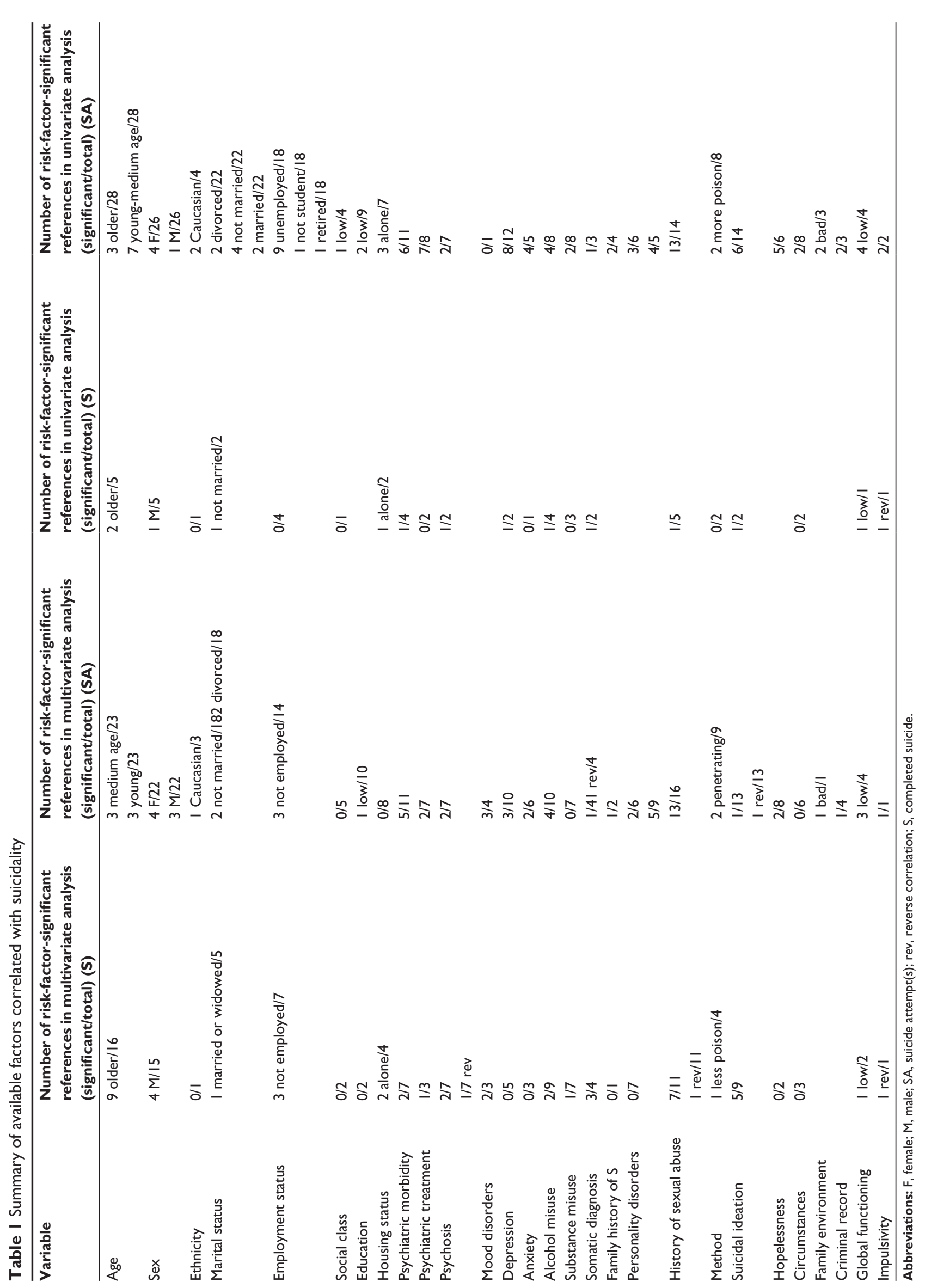



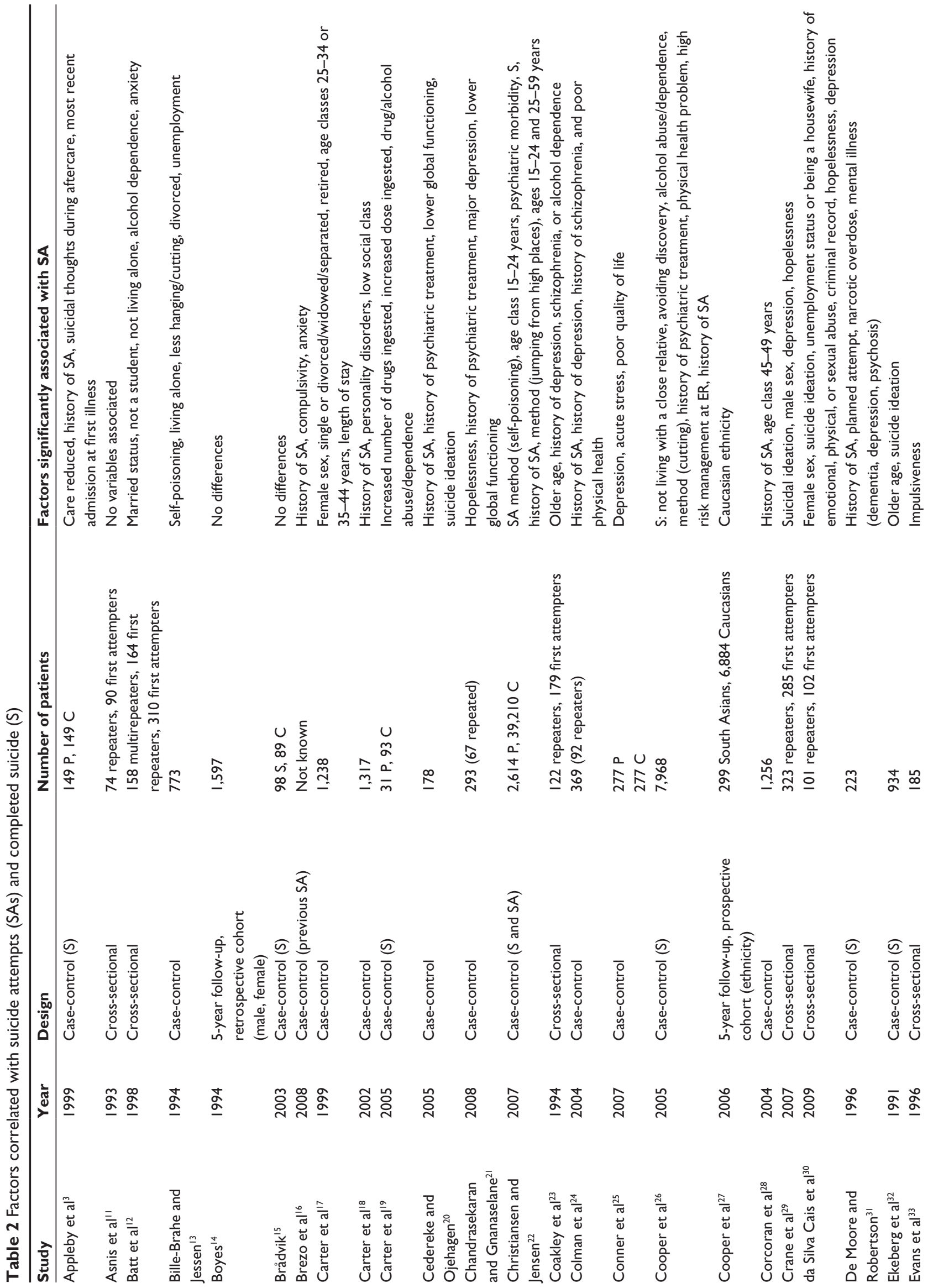

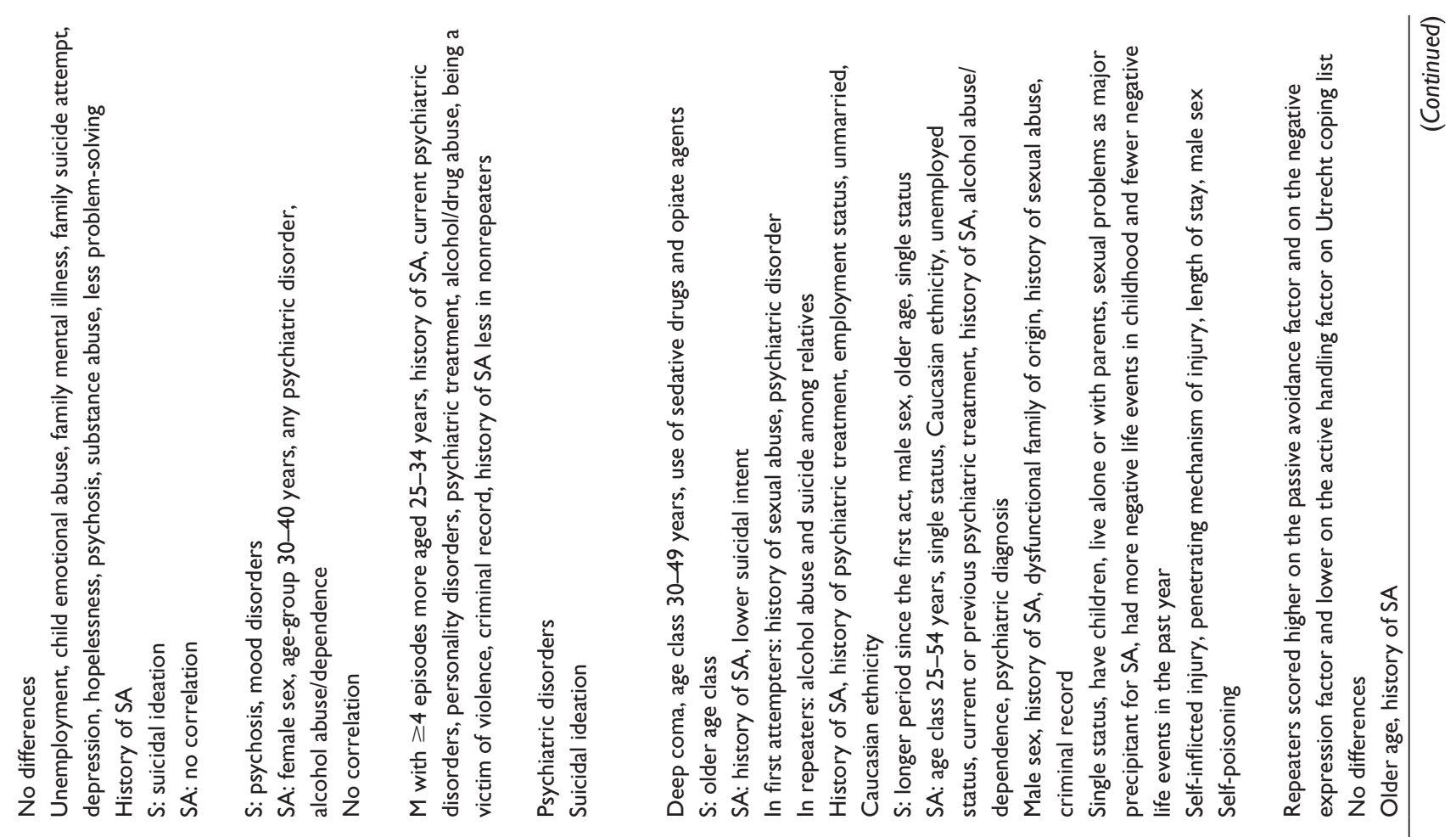

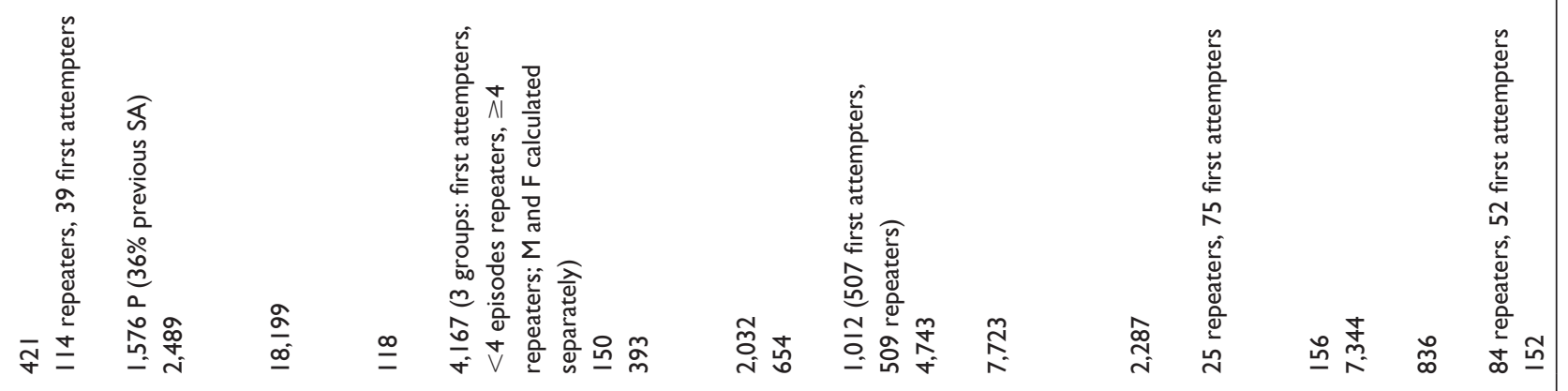
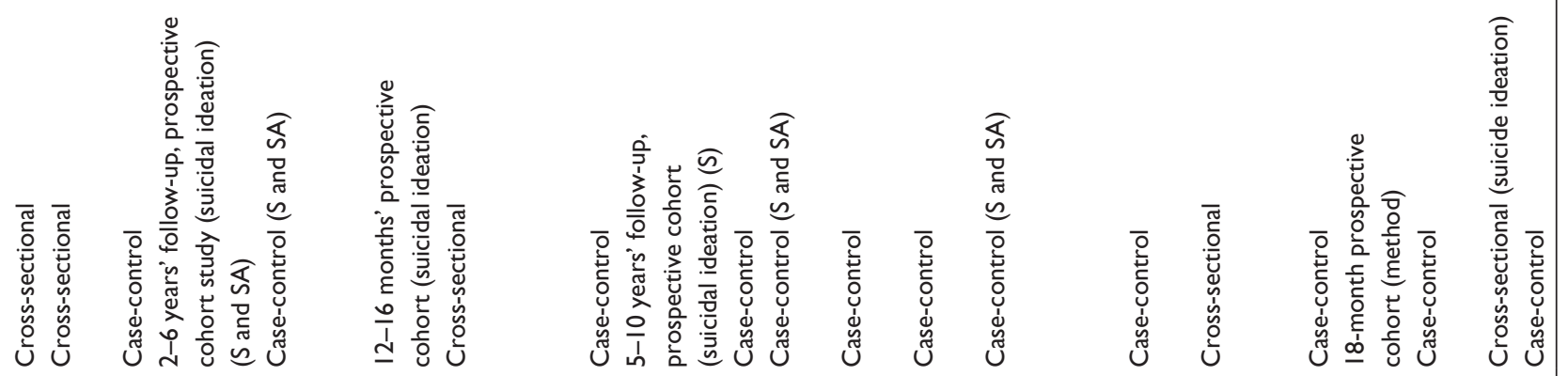

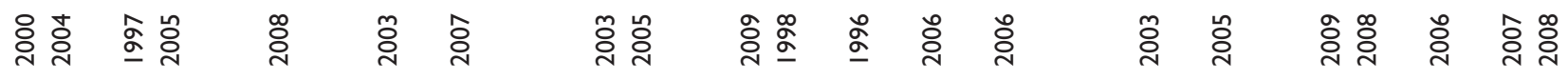

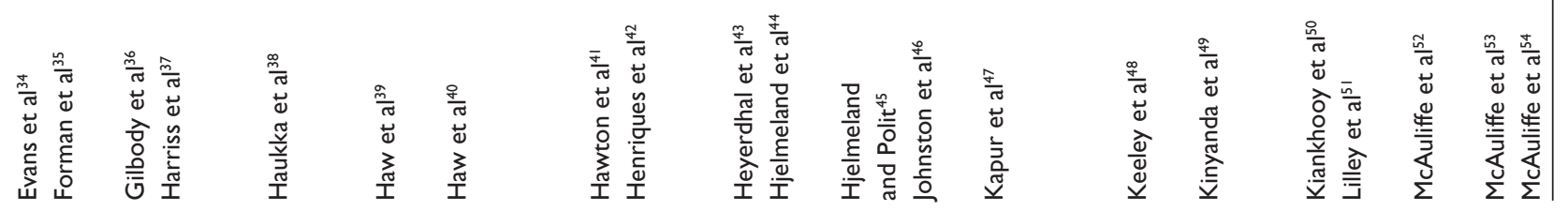



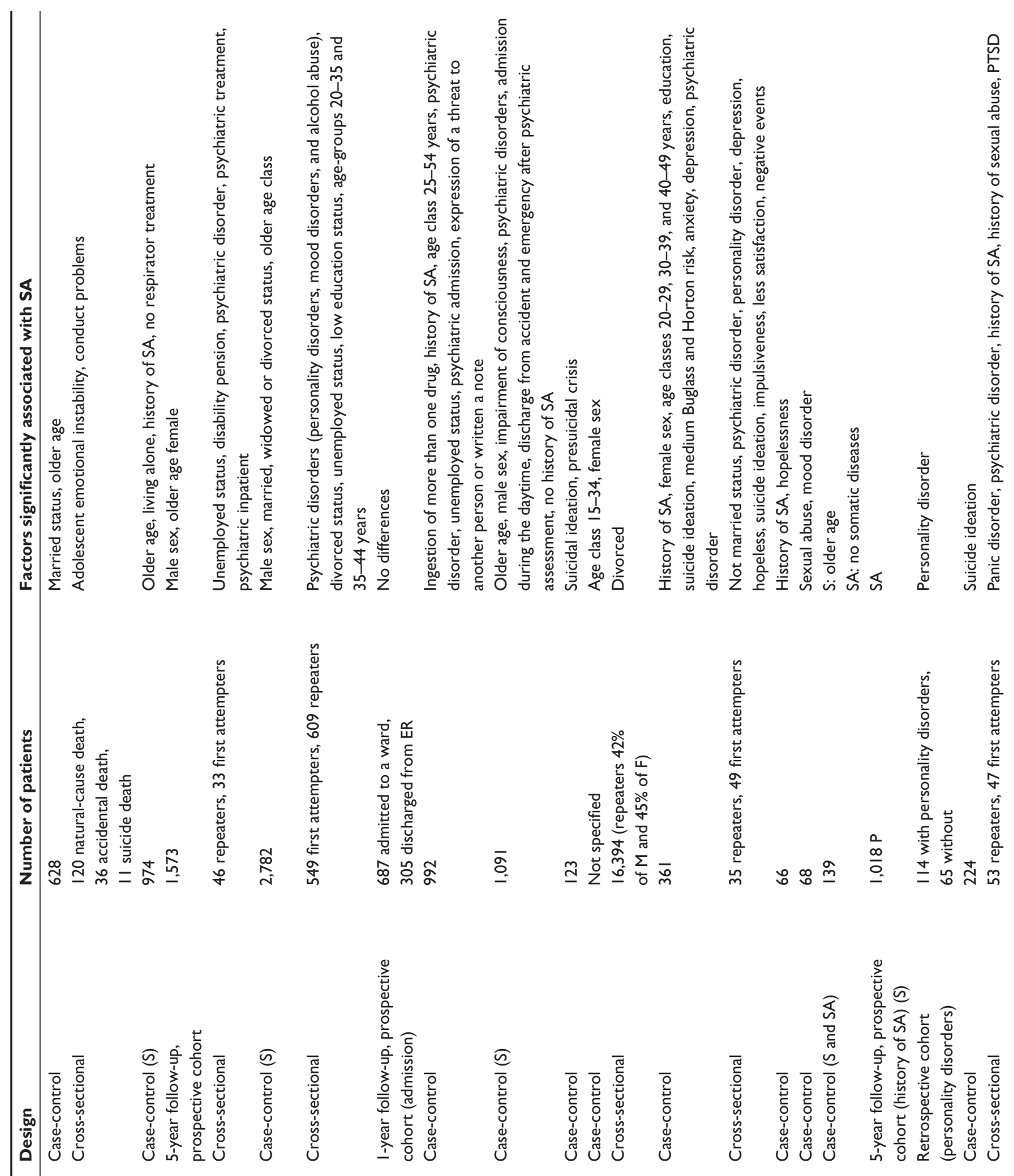

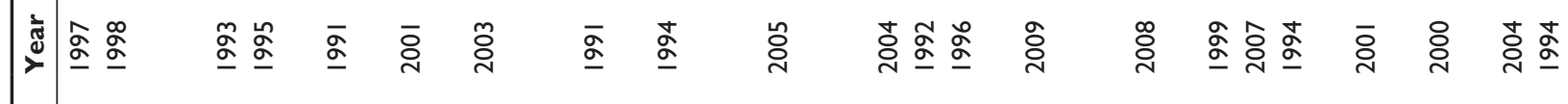
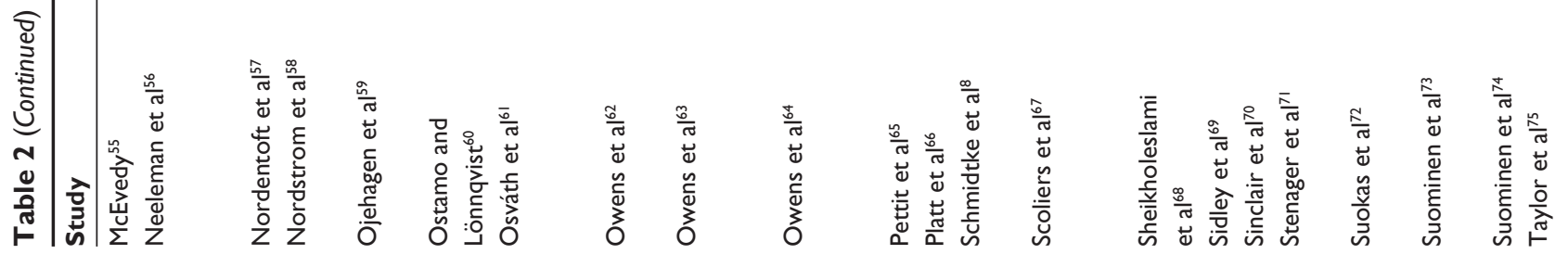


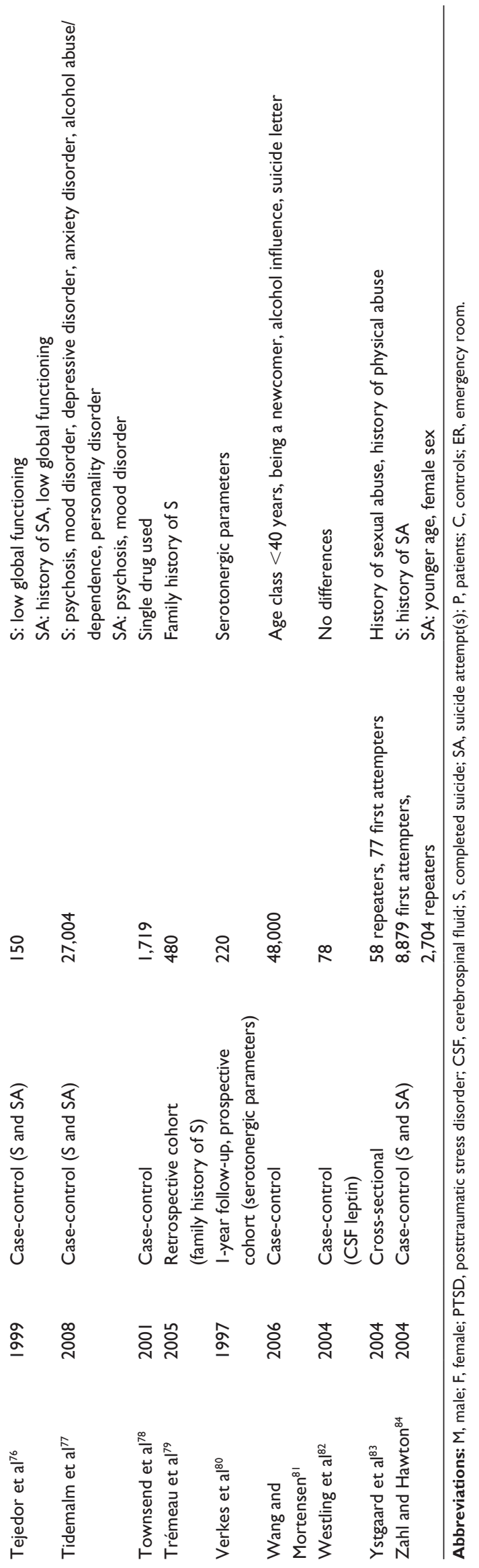

predictors for SA and $\mathrm{S}$, does not seem as strong for repeated SA, while it remains consistent for S. In several cases, no apparent risk factor was detected, and it makes it difficult to prevent fatal and nonfatal attempts.

A large multicenter prospective investigation of first SAs should be undertaken comparing different countries and differing social and cultural backgrounds and settings within each country.

\section{Acknowledgments}

Jennifer Covino, $\mathrm{PhD}$ and Countney Clabby, $\mathrm{PhD}$, for their help on the data collection, and Ettore Beghi, MD, for critically reviewing the study proposal.

\section{Disclosure}

The authors report no conflicts of interest in this work.

\section{References}

1. Bertolote JM, Fleischmann A, De Leo D, et al. Suicide attempts, plans, and ideation in culturally diverse sites: the WHO SUPRE-MISS community survey. Psychol Med. 2005;35(10):1457-1465.

2. Mościcki EK. Identification of suicide risk factors using epidemiologic studies. Psychiatr Clin North Am. 1997;20(3):499-517.

3. Appleby L, Dennehy JA, Thomas CS, Faragher EB, Lewis G. Aftercare and clinical characteristics of people with mental illness who commit suicide: a case-control study. Lancet. 1999;353(9162):1397-1400.

4. Blumenthal SJ, Kupfer DJ, editors. Suicide over the Life Cycle: Risk Factors, Assessment, and Treatment of Suicidal Patients. Washington: American Psychiatric Association; 1990.

5. Pokorny AD. Prediction of suicide in psychiatric patients. Report of a prospective study. Arch Gen Psychiatry. 1983;40(3):249-257.

6. Hughes T, Owens D. Can attempted suicide (deliberate self-harm) be anticipated or prevented? Curr Opin Psychiatry. 1995;8(2):76-79.

7. Owens D, Horrocks J, House A. Fatal and non-fatal repetition of self-harm. Systematic review. Br J Psychiatry. 2002;181:193-199.

8. Schmidtke A, Bille-Brahe U, DeLeo D, et al. Attempted suicide in Europe: rates, trends and sociodemographic characteristics of suicide attempters during the period 1989-1992. Results of the WHO/ EURO Multicentre Study on Parasuicide. Acta Psychiatr Scand. 1996;93(5):327-338.

9. Silverman MM, Berman AL, Sanddal ND, O'Carroll PW, Joiner TE. Rebuilding the tower of Babel: a revised nomenclature for the study of suicide and suicidal behaviors. Part 1: Background, rationale and methodology. Suicide Life Threat Behav. 2007;37(3):248-263.

10. Silverman MM, Berman AL, Sanddal ND, O'Carroll PW, Joiner TE. Rebuilding the tower of Babel: a revised nomenclature for the study of suicide and suicidal behaviors. Part 2: Suicide-related ideations, communications, and behaviors. Suicide Life Threat Behav. 2007;37(3): 264-277.

11. Asnis GM, Friedman TA, Sanderson WC, Kaplan ML, van Praag HM, Harkavy-Friedman JM. Suicidal behaviors in adult psychiatric outpatients, I: Description and prevalence. Am J Psychiatry. 1993;150(1): 108-112.

12. Batt A, Eudier F, Le Vaou P, et al. Repetition of parasuicide: risk factors in general hospital referred patients. J Ment Health. 1998;7(3): 285-297.

13. Bille-Brahe U, Jessen G. Repeated suicidal behavior: a two-year follow-up. Crisis. 1994;15(2):77-82.

14. Boyes AP. Repetition of overdose: a retrospective 5-year study. J Adv Nurs. 1994;20(3):462-468. 
15. Brådvik L. Suicide after suicide attempt in severe depression: a long-term follow-up. Suicide Life Threat Behav. 2003;33(4): 381-388.

16. Brezo J, Paris J, Hébert M, Vitaro F, Tremblay R, Turecki G. Broad and narrow personality traits as markers of one-time and repeated suicide attempts: a population-based study. BMC Psychiatry. 2008;8:15.

17. Carter GL, Whyte IM, Ball K, et al. Repetition of deliberate selfpoisoning in an Australian hospital-treated population. Med J Aust. 1999;170(7):307-311.

18. Carter GL, Clover KA, Bryant JL, Whyte IM. Can the Edinburgh Risk of Repetition Scale predict repetition of deliberate selfpoisoning in an Australian clinical setting? Suicide Life Threat Behav. 2002;32(3):230-239.

19. Carter G, Reith DM, Whyte IM, McPherson M. Repeated selfpoisoning: increasing severity of self-harm as a predictor of subsequent suicide. Br J Psychiatry. 2005;186:253-257.

20. Cedereke M, Ojehagen A. Prediction of repeated parasuicide after 1-12 months. Eur Psychiatry. 2005;20(2):101-109.

21. Chandrasekaran R, Gnanaselane J. Predictors of repeat suicidal attempts after first-ever attempt: a two-year follow-up study. Hong Kong $J$ Psychiatry. 2008;18(4):131-135.

22. Christiansen E, Jensen BF. Risk of repetition of suicide attempt, suicide or all deaths after an episode of attempted suicide: a register-based survival analysis. Aust N Z J Psychiatry. 2007;41(3):257-265.

23. Coakley F, Hayes C, Fennell J, Johnson Z. A study of deliberate self-poisoning in a Dublin Hospital 1986-1990. Ir J Psychol Med. 1994;11(2):70-72.

24. Colman I, Newman SC, Schopflocher D, Bland RC, Dyck RJ. A multivariate study of predictors of repeat parasuicide. Acta Psychiatr Scand. 2004;109(4):306-312.

25. Conner KR, Phillips MR, Meldrum SC. Predictors of low-intent and high-intent suicide attempts in rural China. Am J Public Health. 2007;97(10):1842-1846.

26. Cooper J, Kapur N, Webb R, et al. Suicide after deliberate self-harm: a 4-year cohort study. Am J Psychiatry. 2005;162(2):297-303.

27. Cooper J, Husain N, Webb R, et al. Self-harm in the UK: differences between South Asians and Whites in rates, characteristics, provision of service and repetition. Soc Psychiatry Psychiatr Epidemiol. 2006; 41(10): 782-788

28. Corcoran P, Keeley HS, O'Sullivan M, Perry IJ. The incidence and repetition of attempted suicide in Ireland. Eur J Public Health. 2004;14(1):19-23.

29. Crane C, Williams JM, Hawton K, et al. The association between life events and suicide intent in self-poisoners with and without a history of deliberate self-harm: a preliminary study. Suicide Life Threat Behav. 2007;37(4):367-378.

30. da Silva Cais CF, Stefanello S, Fabrício Mauro ML, Vaz Scavacini de Freitas G, Botega NJ. Factors associated with repeated suicide attempts. Preliminary results of the WHO Multisite Intervention Study on Suicidal Behavior (SUPRE-MISS) from Campinas, Brazil. Crisis. 2009;30(2):73-78.

31. De Moore GM, Robertson AR. Suicide in the 18 years after deliberate selfharm: a prospective study. Br J Psychiatry. 1996;169(4):489-494.

32. Ekeberg O, Ellingsen O, Jacobsen D. Suicide and other causes of death in a five-year follow-up of patients treated for self-poisoning in Oslo. Acta Psychiatr Scand. 1991;83(6):432-437.

33. Evans J, Platts H, Liebenau A. Impulsiveness and deliberate self-harm: a comparison of "first-timers" and "repeaters." Acta Psychiatr Scand. 1996;93(5):378-380.

34. Evans J, Reeves B, Platt H, et al. Impulsiveness, serotonin genes and repetition of deliberate self-harm (DSH). Psychol Med. 2000;30(6): $1327-1334$.

35. Forman EM, Berk MS, Henriques GR, Brown GK, Beck AT. History of multiple suicide attempts as a behavioral marker of severe psychopathology. Am J Psychiatry. 2004;161(3):437-443.

36. Gilbody S, House A, Owens D. The early repetition of deliberate self harm. J R Coll Physicians Lond. 1997;31(2):171-172.
37. Harriss L, Hawton K, Zahl D. Value of measuring suicidal intent in the assessment of people attending hospital following self-poisoning or self-injury. Br J Psychiatry. 2005;186:60-66.

38. Haukka J, Suominen K, Partonen T, et al. Determinants and outcomes of serious attempted suicide: a nationwide study in Finland, 1996-2003. Am J Epidemiol. 2008;167(10):1155-1163.

39. Haw C, Hawton K, Houston K, Townsend E. Correlates of relative lethality and suicidal intent among deliberate self-harm patients. Suicide Life Threat Behav. 2003;33(4):353-364.

40. Haw C, Bergen H, Casey D, Hawton K. Repetition of deliberate selfharm: a study of the characteristics and subsequent deaths in patients presenting to a general hospital according to extent of repetition. Suicide Life Threat Behav. 2007;37(4):379-396.

41. Hawton K, Houston K, Haw C, Townsend E, Harriss L. Comorbidity of axis I and axis II disorders in patients who attempted suicide. $\mathrm{Am} \mathrm{J}$ Psychiatry. 2003;160(8):1494-1500.

42. Henriques G, Wenzel A, Brown GK, Beck AT. Suicide attempters' reaction to survival as a risk factor for eventual suicide. Am J Psychiatry. 2005;162(11):2180-2182

43. Heyerdahl F, Bjornaas MA, Dahl R, et al. Repetition of acute poisoning in Oslo: 1-year prospective study. Br J Psychiatry. 2009;194(1): 73-79.

44. Hjelmeland H, Stiles TC, Bille-Brahe U, et al. Parasuicide: the value of suicidal intent and various motives as predictors of future suicidal behavior. Arch Suicide Res. 1998;4(3):209-225.

45. Hjelmeland H, Polit C. Repetition of parasuicide: a predictive study. Suicide Life Threat Behav. 1996;26(4):395-404.

46. Johnston A, Cooper J, Webb R, Kapur N. Individual- and area-level predictors of self-harm repetition. Br J Psychiatry. 2006;189:416-421.

47. Kapur N, Cooper J, King-Hele S, et al. The repetition of suicidal behavior: a multicenter cohort study. J Clin Psychiatry. 2006;67(10): 1599-1609.

48. Keeley H, O'Sullivan M, Corcoran P. Background stressors and deliberate self-harm. Prospective case note study in southern Ireland. Psychiatr Bull R Coll Psychiatr. 2003;27(11):411-415.

49. Kinyanda E, Hjelmeland H, Musisi S, Kigozi F, Walugembe J. Repetition of deliberate self-harm as seen in Uganda. Arch Suicide Res. 2005;9(4):333-344.

50. Kiankhooy A, Crookes B, Privette A, Osler T, Sartorelli K. Fait accompli: suicide in a rural trauma setting. J Trauma. 2009;67(2):366-371.

51. Lilley R, Owens D, Horrocks J, et al. Hospital care and repetition following self-harm: multicentre comparison of self-poisoning and self-injury. Br J Psychiatry. 2008;192(6):440-445.

52. McAuliffe C, Corcoran P, Keeley HS, et al. Problem-solving ability and repetition of deliberate self-harm: a multicentre study. Psychol Med. 2006;36(1):45-55.

53. McAuliffe C, Arensman E, Keeley HS, Corcoran P, Fitzgerald AP. Motives and suicide intent underlying hospital treated deliberate selfharm and their association with repetition. Suicide Life Threat Behav. 2007;37(4):397-408.

54. McAuliffe C, Corcoran P, Hickey P, McLeavey BC. Optional thinking ability among hospital-treated deliberate self-harm patients: a 1-year follow-up study. Br J Clin Psychol. 2008;47(Pt 1):43-58.

55. McEvedy CJ. Trends in self-poisoning: admissions to a central London hospital, 1991-1994. J R Soc Med. 1997;90(9):496-498.

56. Neeleman J, Wessely S, Wadsworth M. Predictors of suicide, accidental death, and premature natural death in a general-population birth cohort. Lancet. 1998;351(9096):93-97.

57. Nordentoft M, Breum L, Munck LK, Nordestgaard AG, Hunding A, Laursen Bjaeldager PA. High mortality by natural and unnatural causes: a 10 year follow up study of patients admitted to a poisoning treatment centre after suicide attempts. BMJ. 1993;306(6893):1637-1641.

58. Nordström P, Samuelsson M, Asberg M. Survival analysis of suicide risk after attempted suicide. Acta Psychiatr Scand. 1995;91(5):336-340.

59. Ojehagen A, Regnéll G, Träskman-Bendz L. Deliberate self-poisoning: repeaters and nonrepeaters admitted to an intensive care unit. Acta Psychiatr Scand. 1991;84(3):266-271. 
60. Ostamo A, Lönnqvist J. Excess mortality of suicide attempters. Soc Psychiatry Psychiatr Epidemiol. 2001;36(1):29-35.

61. Osváth P, Kelemen G, Erdös MB, Vörös V, Fekete S. The main factors of repetition: review of some results of the Pecs Center in the WHO/ EURO Multicentre Study on Suicidal Behaviour. Crisis. 2003;24(4): $151-154$.

62. Owens D, Dennis M, Jones S, Dove A, Dave S. Self-poisoning patients discharged from accident and emergency: risk factors and outcome. J R Coll Physicians Lond. 1991;25(3):218-222.

63. Owens D, Dennis M, Read S, Davis N. Outcome of deliberate selfpoisoning. An examination of risk factors for repetition. BrJ Psychiatry. 1994;165(6):797-801.

64. Owens D, Wood C, Greenwood DC, Hughes T, Dennis M. Mortality and suicide after non-fatal self-poisoning: 16-year outcome study. $\mathrm{Br}$ J Psychiatry. 2005; 187:470-475.

65. Pettit JW, Joiner TE Jr, Rudd MD. Kindling and behavioral sensitization: are they relevant to recurrent suicide attempts? $J$ Affect Disord. 2004;83(2-3):249-252.

66. Platt S, Bille-Brahe U, Kerkhof A, et al. Parasuicide in Europe: the WHO/ EURO multicentre study on parasuicide. I. Introduction and preliminary analysis for 1989. Acta Psychiatr Scand. 1992;85(2):97-104.

67. Scoliers G, Portzky G, van Heeringen K, Audenaert K. Sociodemographic and psychopathological risk factors for repetition of attempted suicide: a 5-year follow-up study. Arch Suicide Res. 2009;13(3):201-213.

68. Sheikholeslami H, Kani C, Ziaee A. Attempted suicide among Iranian population. Suicide Life Threat Behav. 2008;38(4):456-466.

69. Sidley GL, Calam R, Wells A, Hughes T, Whitaker K. The prediction of parasuicide repetition in a high-risk group. Br J Clin Psychol. 1999; 38(Pt 4):375-386.

70. Sinclair JM, Crane C, Hawton K, Williams JM. The role of autobiographical memory specificity in deliberate self-harm: correlates and consequences. J Affect Disord. 2007;102(1-3):11-18.

71. Stenager EN, Stenager E, Jensen K. Attempted suicide, depression and physical diseases: a 1-year follow-up study. Psychother Psychosom. 1994;61(1-2):65-73

72. Suokas J, Suominen K, Isometsä E, Ostamo A, Lönnqvist J. Long-term risk factors for suicide mortality after attempted suicide - findings of a 14-year follow-up study. Acta Psychiatr Scand. 2001;104(2): $117-121$.

73. Suominen KH, Isometsä ET, Henriksson MM, Ostamo AI, Lönnqvist JK. Suicide attempts and personality disorder. Acta Psychiatr Scand. 2000;102(2):118-125.

74. Suominen K, Isometsä E, Ostamo A, Lönnqvist J. Level of suicidal intent predicts overall mortality and suicide after attempted suicide: a 12-year follow-up study. BMC Psychiatry. 2004;4:11.
75. Taylor CJ, Kent GG, Huws RW. A comparison of the backgrounds of first time and repeated overdose patients. J Accid Emerg Med. 1994;11(4):238-242.

76. Tejedor MC, Díaz A, Castillón JJ, Pericay JM. Attempted suicide: repetition and survival - findings of a follow-up study. Acta Psychiatr Scand. 1999;100(3):205-211.

77. Tidemalm D, Långström N, Lichtenstein P, Runeson B. Risk of suicide after suicide attempt according to coexisting psychiatric disorder: Swedish cohort study with long term follow-up. BMJ. 2008; 337:a2205

78. Townsend E, Hawton K, Harriss L, Bale E, Bond A. Substances used in deliberate self-poisoning 1985-1997: trends and associations with age, gender, repetition and suicide intent. Soc Psychiatry Psychiatr Epidemiol. 2001;36(5):228-234.

79. Trémeau F, Staner L, Duval F, et al. Suicide attempts and family history of suicide in three psychiatric populations. Suicide Life Threat Behav. 2005;35(6):702-713.

80. Verkes RJ, Fekkes D, Zwinderman AH, et al. Platelet serotonin and $[3 \mathrm{H}]$ paroxetine binding correlate with recurrence of suicidal behavior Psychopharmacology (Berl). 1997;132(1):89-94.

81. Wang AG, Mortensen G. Core features of repeated suicidal behaviour: a long-term follow-up after suicide attempts in a low-suicide-incidence population. Soc Psychiatry Psychiatr Epidemiol. 2006;41(2): 103-107.

82. Westling S, Ahrén B, Träskman-Bendz L, Westrin A. Low CSF leptin in female suicide attempters with major depression. $J$ Affect Disord. 2004;81(1):41-48.

83. Ystgaard M, Hestetun I, Loeb M, Mehlum L. Is there a specific relationship between childhood sexual and physical abuse and repeated suicidal behavior? Child Abuse Negl. 2004;28(8):863-875.

84. Zahl DL, Hawton K. Repetition of deliberate self-harm and subsequent suicide risk: long-term follow-up study of 11,583 patients. $\mathrm{Br} J$ Psychiatry. 2004;185:70-75.

85. Diekstra RF. Suicide and suicide attempts in the European Economic Community: an analysis of trends, with special emphasis upon trends among the young. Suicide Life Threat Behav. 1985;15(1):27-42.

86. Reulbach U, Bleich S. Suicide risk after a suicide attempt. BMJ. 2008;337:a2512.

87. Kapur N, House A, May C, Creed F. Service provision and outcome for deliberate self-poisoning in adults - results from a six centre descriptive study. Soc Psychiatry Psychiatr Epidemiol. 2003;38(7):390-395. 


\section{Publish your work in this journal}

Neuropsychiatric Disease and Treatment is an international, peerreviewed journal of clinical therapeutics and pharmacology focusing on concise rapid reporting of clinical or pre-clinical studies on a range of neuropsychiatric and neurological disorders. This journal is indexed on PubMed Central, the 'PsycINFO' database and CAS.

The manuscript management system is completely online and includes a very quick and fair peer-review system, which is all easy to use. Visit http://www.dovepress.com/testimonials.php to read real quotes from published authors.

\footnotetext{
Submit your manuscript here: http://www.dovepress.com/neuropsychiatric-disease-and-treatment-journal
} 